\title{
ANALYTICAL MODELLING OF THE LINEAR WEAR OF THE INSIDE OF A PIPE TRANSPORTING LOOSE MATERIALS
}

\author{
Andrzej CHMIELOWIEC ${ }^{\mathbf{1}}$, Wojciech HOMIK ${ }^{2}$ \\ ${ }^{1}$ Rzeszow University of Technology, achmie@ prz.edu.pl \\ ${ }^{2}$ Rzeszow University of Technology, whomik@ prz.edu.pl
}

Abstract

This paper presents the results of an analysis of the linear wear of the inside of a pipe transporting loose materials. The aim is to present a mathematical model simulating the abrasive wear of individual elements of a transport pipe, depending on the volume of transported material. The model presented in this paper was developed based on the measurement data obtained from a dismantled transport system used in a railway handling terminal.

Keywords: loose materials, linear wear, analytical model, grain flow

\section{ANALITYCZNE MODELOWANIE ŚCIERALNOŚCI WNĘTRZA RURY TRANSPORTUJĄCEJ MATERIAŁY SYPKIE}

Streszczenie

W artykule przedstawiono wyniki analizy zużycia liniowego materiału wewnątrz rury służącej do transportu materiałów sypkich. Celem artykułu jest zaprezentowanie modelu matematycznego, który pozwala symulować zużycie poszczególnych elementów rury transportowej w zależności od ilości przesypanego materiału. Prezentowany w artykule model opracowany został w oparciu o dane pomiarowe uzyskane ze zdemontowanego systemu transportowego wykorzystywanego w kolejowym terminalu przeładunkowym.

Słowa kluczowe: materiały sypkie, zużycie, zużycie liniowe, model analityczny, przepływ ziarna

\section{INTRODUCTION}

Fast wear of transporting elements in silos and handling terminals poses a real problem. Many aspects of grain flow in such transport systems have been considered in the literature. Bevereloo [3], Brown [4] and Chang [7, 8] were among the earliest pioneers in the field. Over the years many authors have considered fluctuations, wall friction and mechanical wear $[9,10,22,25]$. Recent years also show that the mentioned problems are still relevant and give inspiration to the construction of analytical models of transport processes in silos systems [5, 6, $14,15,18,19,20]$. What is more, the transport of wet grain, causing corrosive and mechanical wear, brings an even greater problem [13, 17, 23, 24, 27]. Such conditions of transporting materials necessitate relatively frequent replacements of damaged elements, which translates into higher operating costs and causes stoppages. With computers being so ubiquitous these days, the transport of loose material is usually simulated with the use of discrete methods: specifically developed software simulates the movement of each of the thousands of transported particles. The prevalence of this approach is also proved by the substantial number of IT tools supporting it and the everincreasing number of publications dealing with this issue. The IT tools and mathematical models are mostly based on the Discrete Element Method (DEM). [11, 28] describe how to use and apply Yade, an open-source framework focused on DEM $[11,28]$. A lot of attention is also paid to the creation of an effective model simulating the movement of loose material particles $[1,12,16$, $21]$. The authors of $[29,30]$, who performed an accurate analysis of the usefulness of various variants of the Discrete Element Method, give a precise description of DEM's development over the years. Special approach is used to simulate the movement of wet particles $[2,26]$. In this paper the focus is intentionally shifted from the discrete model (DEM) to the analytical one, as only the latter makes it possible to effectively simulate the movement of a vast number of transported particles.

\section{THEORETICAL MODEL OF LINEAR WEAR OF THE INSIDE OF A TRANSPORT PIPE}

The proposed model assumes that loose material (corn, rape) is transported through a circular pipe angled at $\alpha=\pi / 6=30^{\circ}$ to the horizontal (as shown in Figure 1 and 2).

Moreover, it is assumed that the angle of slip of the transported material is $\beta$. It must be stressed that 
both corn and rape have different angles of slip, depending on variety. However, the differences are minor and the vast majority of grain materials have the angle of slip equal to $30^{\circ} \pm 2^{\circ}$. Therefore, our numerical analysis assumes an average angle of slip equal to $\beta=\pi / 6=30^{\circ}$.

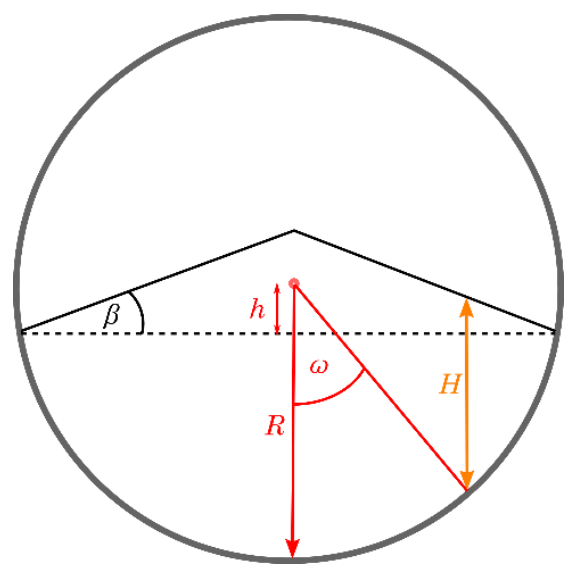

Fig. 1. Cross-section of a transport pipe of radius $R$.

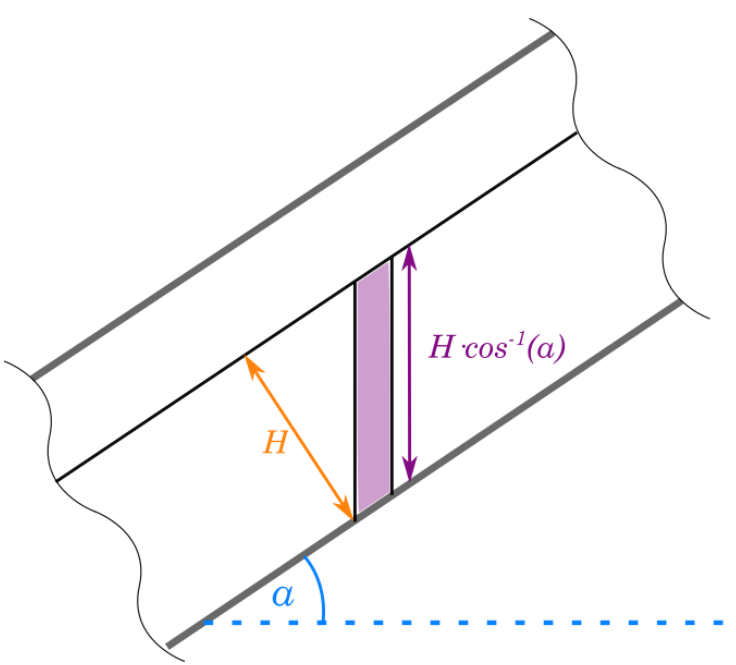

Fig. 2. Longitudinal section of a transport pipe angled at $\alpha$ to the horizontal

Moreover, we assumed that the linear wear of the material inside a transport pipe is proportional to the pressure exerted by the loose material moving inside it. Let us assume that there are two sources of this pressure:

1. pressure exerted by the movement of loose material (pressure independent of the angle $\omega$ ),

2. pressure exerted by the weight of loose material (pressure dependent of the angle $\omega$ ).

This assumption underpins the proposed model and was made based on observation and statistical analysis of the measurement data. Later on in the paper we will demonstrate that this approach is supported and justified by a positive verification of the hypothesis on the assumptions made by us. In addition, we assume that the pipe is of radius $R$ and that the distance between the base of the pile built in the pipe and the geometrical axis of symmetry of the pipe equals to $h$ (as shown in Figure 1). Based on these assumptions we develop the function of pressure:

$$
p(\omega)=p_{0}+p_{1} f(\omega)
$$

where $p_{0}$ is the constant pressure dependent on the speed at which the material is fed, and a $p_{1}$ is the pressure put by the weight of the loose material.

Let us assume that the height of a narrow column of the loose material is $H \cdot \cos ^{-1} \alpha$ (see Figure 2) and that its cross-section area is $\Delta S$ (see Figure 3). Let $Q=$ $\rho g \Delta S H \cos ^{-1} \alpha$ be the weight of the column $(\rho-$ density of the material, $g-$ gravitational acceleration, $\Delta S-$ cross-section area of the column of loose material shown in Figure $3, H \cos ^{-1} \alpha-$ height of the column of loose material shown in Figure 2) By trigonometric relationships we calculate the pressure exerted by the column on the wall of the transport pipe:

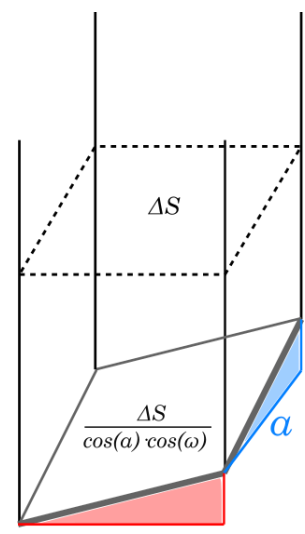

$\omega$

Fig. 3. Pictorial diagram of a column of loose material of with a cross-section area $\Delta S$ putting pressure on the transport pipe

$$
p_{1} f(\omega)=\frac{Q \cos \alpha \cos \omega}{\Delta S \cos ^{-1} \alpha \cos ^{-1} \omega}=
$$

$$
\rho g H \cos \alpha \cos ^{2} \omega \text {. }
$$

As shown in Figure 1, the height $H$ depends on the angle $\omega$. Using simple trigonometric relationships, we obtain the following formula:

$$
\begin{aligned}
H(\omega)= & (R \cos \omega-h)+ \\
& \tan \beta\left(\sqrt{R^{2}-h^{2}}-R \sin |\omega|\right) .
\end{aligned}
$$

Finally, we obtain:

$$
\begin{aligned}
f(\omega)= & \cos ^{2} \omega((R \cos \omega-h)+ \\
& \left.\tan \beta\left(\sqrt{R^{2}-h^{2}}-R \sin |\omega|\right)\right),
\end{aligned}
$$

which for $h=0$ can be simplified to:

$$
\begin{aligned}
f_{0}(\omega)= & \cos ^{2} \omega(R \cos \omega- \\
& R \tan \beta \sin |\omega|+R \tan \beta) .
\end{aligned}
$$

Figure 4 shows the graph of function $f_{0}(\omega)$ for $R$ $=1$ and $\tan \beta=0.577$. Please note that the unit of measure $R$ was intentionally omitted so that the graph illustrates only the shape of the function $f_{0}(\omega)$. 


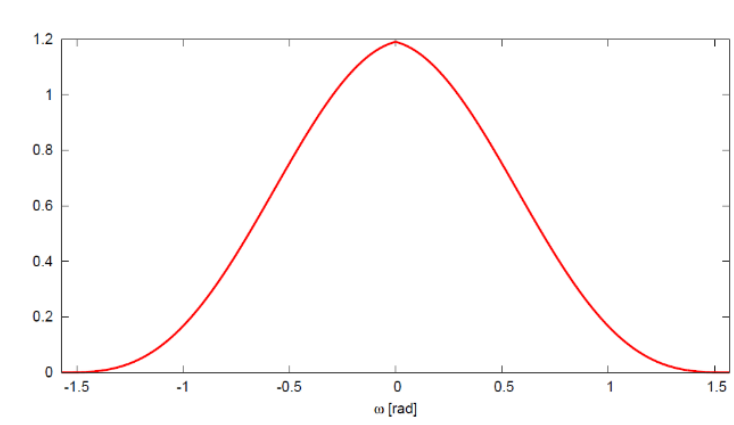

Fig. 4. Graph of function $f_{0}(\omega)$ for $R=1$ and $\tan \beta=0.577$.

At this point we are ready to define the function of linear wear of the material making up the transport pipe $U(\omega, m)[\mathrm{mm}]$, where $m$ is the weight of the transported loose material. Since $U \sim p$ (function $U$ is proportional to pressure $p[\mathrm{~Pa}]$ ) and $U \sim m$ (function $\mathrm{U}$ is proportional to the volume of transported material $m[\mathrm{~kg}]$ ), our linear wear function is given by:

$$
\begin{aligned}
U(\omega, m)= & m U_{0}+ \\
& m U_{1} \cos ^{2} \omega((R \cos \omega-h)+ \\
& \left.\tan \beta\left(\sqrt{R^{2}-h^{2}}-R \sin |\omega|\right)\right) .
\end{aligned}
$$

This formula can be simplified, if we assume that $\omega_{0}$ is the maximum angle at which the transported material adheres to the inside of the pipe. If that is the case, $h=R \cdot \cos \omega_{0}$ and the linear wear function formula can be simplified to:

$$
\begin{aligned}
U(\omega, m)= & m\left(U_{0}+U_{1} R \cos ^{2} \omega(\cos \omega-\right. \\
& \left.\left.\cos \omega_{0}+\tan \beta\left(\sin \omega_{0}-\sin |\omega|\right)\right)\right) .
\end{aligned}
$$

At this point, let us stress that $U_{0}$ and $U_{1}$ are in fact the functions of $\alpha$, i.e. the angle of slip of the transport pipe. In this particular case $\alpha$ is assumed to be $30^{\circ}$ and the calculations have been made based on this assumption. Making $U_{0}$ and $U_{1}$ independent of the angle of slip $\alpha$ is very simple only in the case of $U_{1}$. Formula (2) shows that $U_{I}=$ $K_{I} \cdot \cos (\alpha)$, where $K_{1}$ is a constant depending only on the type of material. Devising a formula for $U_{0}$, however, requires further research and has not been presented in this paper.

\section{ANALYSIS OF THE PROPOSED MODEL AND STATISTICAL VERIFICATION OF ITS CORRECTNESS BASED ON A DISMANTLED TRANSPORT PIPE}

The model presented in the previous section defines the linear wear function $U(\omega, m)$, which determines the reduction of the thickness of the pipe during transport. For the purpose of statistical analysis, the linear wear of the material (steel C30) inside a transport pipe dismantled from a handling terminal was measured. The measurements were made for 5 cross-sections and 14 values of the angle $\omega$ equal to $0^{\circ}, 4.2^{\circ}, 8.4^{\circ}, 12.5^{\circ}, 16.7^{\circ}, 20.9^{\circ}$, $25.1^{\circ}, 29.2^{\circ}, 33.4^{\circ}, 37.6^{\circ}, 41.8^{\circ}, 45.9^{\circ}, 50.1^{\circ}$ and $54.3^{\circ}$ in each cross-section. Figure 5 shows the points in which the thickness of the walls of the transport pipe was measured.
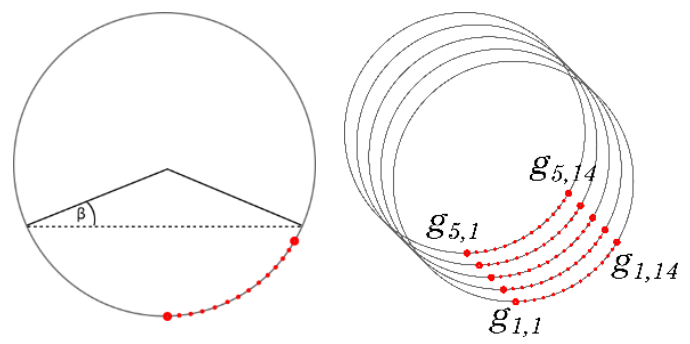

Fig. 5. Measure points of the thickness of a transport pipe.

No measurements were performed for negative angles due to a joint located symmetrically on the other side, which grossly distorted the measurement results. Originally the wall of the transport pipe was $5.3[\mathrm{~mm}]$ thick. After transporting 120 thousand tons of grain, the thickness measured in five points marked in Figure 5 was reduced to the levels shown in Table 1.

Table 1

\begin{tabular}{|c|c|c|c|c|c|}
\hline \multirow{2}{*}{ Angle $\left[^{\circ}\right]$} & \multicolumn{5}{|c|}{$\begin{array}{c}\text { Thickness of the walls of the transport pipe } \\
\text { for each measurement [mm] }\end{array}$} \\
\cline { 2 - 6 } & $g_{1, *}$ & $g_{2, *}$ & $g_{3, *}$ & $g_{4, *}$ & $g_{5, *}$ \\
\hline 0.0 & 4.16 & 4.12 & 4.12 & 4.17 & 4.18 \\
\hline 4.2 & 4.24 & 4.24 & 4.22 & 4.25 & 4.20 \\
\hline 8.4 & 4.28 & 4.32 & 4.29 & 4.30 & 4.27 \\
\hline 12.5 & 4.43 & 4.40 & 4.46 & 4.44 & 4.42 \\
\hline 16.7 & 4.55 & 4.51 & 4.49 & 4.51 & 4.52 \\
\hline 20.9 & 4.62 & 4.69 & 4.65 & 4.60 & 4.62 \\
\hline 25.1 & 4.76 & 4.78 & 4.75 & 4.74 & 4.80 \\
\hline 29.2 & 4.84 & 4.82 & 4.83 & 4.86 & 4.85 \\
\hline 33.4 & 4.94 & 4.94 & 4.96 & 4.98 & 4.95 \\
\hline 37.6 & 5.02 & 5.04 & 5.07 & 5.00 & 5.05 \\
\hline 41.8 & 5.07 & 5.13 & 5.12 & 5.14 & 5.10 \\
\hline 45.9 & 5.09 & 5.12 & 5.12 & 5.11 & 5.12 \\
\hline 50.1 & 5.18 & 5.15 & 5.12 & 5.14 & 5.14 \\
\hline 54.3 & 5.14 & 5.17 & 5.19 & 5.20 & 5.12 \\
\hline
\end{tabular}

Given that originally the wall was $5.3[\mathrm{~mm}]$ thick, the linear wear $\left(u_{i, j}=5.3-g_{i, j}\right)$ of the material is shown in Table 2.

Table 2

\begin{tabular}{|c|c|c|c|c|c|}
\hline \multirow{2}{*}{ Angle [ $\left.{ }^{\circ}\right]$} & \multicolumn{6}{|c|}{$\begin{array}{c}\text { Linear wear of the walls of the transport pipe } \\
\end{array}$} & $u_{1, *}$ & $u_{2, *}$ & $u_{3, *}$ & $u_{4, *}$ & $u_{5, *}$ \\
\cline { 2 - 6 } & 1.14 & 1.18 & 1.18 & 1.13 & 1.12 \\
\hline 0.0 & 1.06 & 1.06 & 1.08 & 1.05 & 1.10 \\
\hline 4.2 & 1.02 & 0.98 & 1.01 & 1.00 & 1.03 \\
\hline 8.4 & 0.87 & 0.90 & 0.84 & 0.86 & 0.88 \\
\hline 12.5 & 0.75 & 0.79 & 0.81 & 0.79 & 0.78 \\
\hline 16.7 & 0.68 & 0.61 & 0.65 & 0.70 & 0.68 \\
\hline 20.9 & 0.54 & 0.52 & 0.55 & 0.56 & 0.50 \\
\hline 25.1 & 0.54 & 0.47 & 0.44 & 0.45 \\
\hline 29.2 & 0.46 & 0.48 & 0.47 & 0.35 \\
\hline 33.4 & 0.36 & 0.36 & 0.34 & 0.32 & 0.35 \\
\hline 37.6 & 0.28 & 0.26 & 0.23 & 0.30 & 0.25 \\
\hline 41.8 & 0.23 & 0.17 & 0.18 & 0.16 & 0.20 \\
\hline 45.9 & 0.21 & 0.18 & 0.18 & 0.19 & 0.18 \\
\hline 50.1 & 0.12 & 0.15 & 0.18 & 0.16 & 0.16 \\
\hline 54.3 & 0.16 & 0.13 & 0.11 & 0.10 & 0.18 \\
\hline
\end{tabular}


By calculating the average values and the measurement error for individual angles, we obtain the following relationships for the linear wear function $U(\omega, m)$ :

Table 3

\begin{tabular}{|c|c|c|}
\hline$U$ function & $\begin{array}{c}\text { Measure avg. } \\
{[\mathrm{mm}]}\end{array}$ & $\begin{array}{c}\text { Measure error } \\
{[\mathrm{mm}]}\end{array}$ \\
\hline$U\left(0.0^{\circ}, 1.2 \mathrm{e} 8\right)$ & 1.15 & \pm 0.08 \\
\hline$U\left(4.2^{\circ}, 1.2 \mathrm{e} 8\right)$ & 1.07 & \pm 0.06 \\
\hline$U\left(8.4^{\circ}, 1.2 \mathrm{e} 8\right)$ & 1.01 & \pm 0.06 \\
\hline$U\left(12.5^{\circ}, 1.2 \mathrm{e} 8\right)$ & 0.87 & \pm 0.07 \\
\hline$U\left(16.7^{\circ}, 1.2 \mathrm{e} 8\right)$ & 0.78 & \pm 0.07 \\
\hline$U\left(20.9^{\circ}, 1.2 \mathrm{e} 8\right)$ & 0.66 & \pm 0.11 \\
\hline$U\left(25.1^{\circ}, 1.2 \mathrm{e} 8\right)$ & 0.53 & \pm 0.07 \\
\hline$U\left(29.2^{\circ}, 1.2 \mathrm{e} 8\right)$ & 0.46 & \pm 0.05 \\
\hline$U\left(33.4^{\circ}, 1.2 \mathrm{e} 8\right)$ & 0.35 & \pm 0.05 \\
\hline$U\left(37.6^{\circ}, 1.2 \mathrm{e} 8\right)$ & 0.26 & \pm 0.08 \\
\hline$U\left(41.8^{\circ}, 1.2 \mathrm{e} 8\right)$ & 0.19 & \pm 0.08 \\
\hline$U\left(45.9^{\circ}, 1.2 \mathrm{e} 8\right)$ & 0.19 & \pm 0.04 \\
\hline$U\left(50.1^{\circ}, 1.2 \mathrm{e} 8\right)$ & 0.15 & \pm 0.07 \\
\hline$U\left(54.3^{\circ}, 1.2 \mathrm{e} 8\right)$ & 0.14 & \pm 0.10 \\
\hline
\end{tabular}

To complete the analysis, we also need to know the radius of the transport pipe, which in this case was $R=130[\mathrm{~mm}]$. The performed examination also showed that the angle at which the transported material adhered to the surface of the pipe ranged approximately from $-60^{\circ}$ to $60^{\circ}$. Therefore, we assume that $\omega_{0}=60^{\circ}$. In addition, we calculate the angle of slip for the transported grain $\beta=30^{\circ}$, for which we assume that $\tan \beta=0.577$. Under these assumptions the formula (7) expressing the $U(\omega, m)$ is given by:

$$
\begin{aligned}
U(\omega, m)= & m\left(U_{0}+130 \cdot U_{1} \cos ^{2} \omega(\cos \omega-\right. \\
& 0.58 \sin |\omega|-0.005)) .
\end{aligned}
$$

Using the least squares method we determine the following coefficients of the linear wear function:

1. $U_{0}=1.52 \mathrm{e}-10[\mathrm{~mm} / \mathrm{kg}]$,

2. $U_{l}=7.03 \mathrm{e}-11[\mathrm{~mm} / \mathrm{kg}]$.

Please note that $U_{0}$ and $U_{1}$ were calculated for a specific material making up the transport pipe, namely C30 steel. $U_{0}$ and $U_{1}$ may differ depending on the material and should thus be determined empirically. Finally, we obtain:

$$
\begin{gathered}
U(\omega, m)=\frac{m}{10^{10}}\left(1.52+0.703 \cos ^{2} \omega(\cos \omega-\right. \\
0.58 \sin |\omega|-0.005)) .
\end{gathered}
$$

Figure 6 presents a graph of the function of linear wear of the material making up the inside of the transport pipe $U(\omega, 1.2 \mathrm{e} 8)$. It confronts the results obtained in the proposed model (solid red line) with the measurements made for a real system for transporting grain (blue error bars). As you can see, all measuring points of the real system conform with the theoretical model to an accuracy of the measurement error. Consequently, we can assume that the hypothesis on the correctness of the proposed model is true.

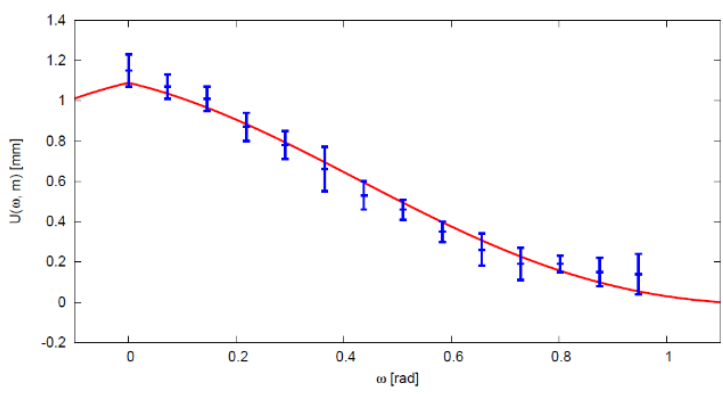

Fig. 6 Graph of the linear wear function $U(\omega, 1.2 \mathrm{e} 8)$

Figure 7 presents a polar graph of the linear wear function. One can easily see that the wear of the transport pipe is extremely heterogeneous.

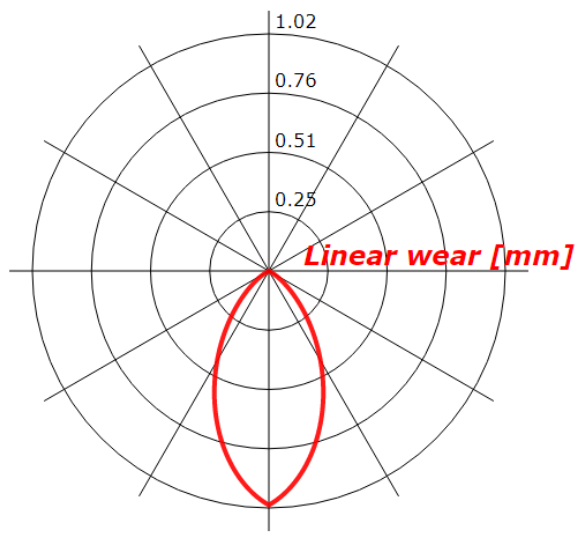

Fig. 7. Polar graph of the linear wear function $U(\omega, 1.2 \mathrm{e} 8)$ without pipe rotation.

A very natural way to make a pipe more durable is its periodic rotation. Figures 8, 9 and 10 present a polar graph of the linear wear function with pipe rotation. The reader can see that periodic rotation by the angle of $30^{\circ}$ gives almost homogenous distribution of the linear wear.

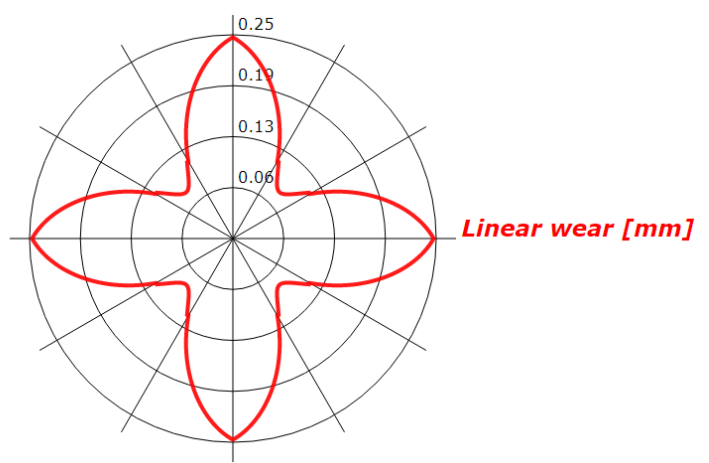

Fig. 8 Polar graph of the linear wear function $U(\omega, 1.2 \mathrm{e} 8)$ with pipe rotation $\left(90^{\circ}\right.$ every $0.3 \mathrm{e} 8[\mathrm{~kg}])$. 


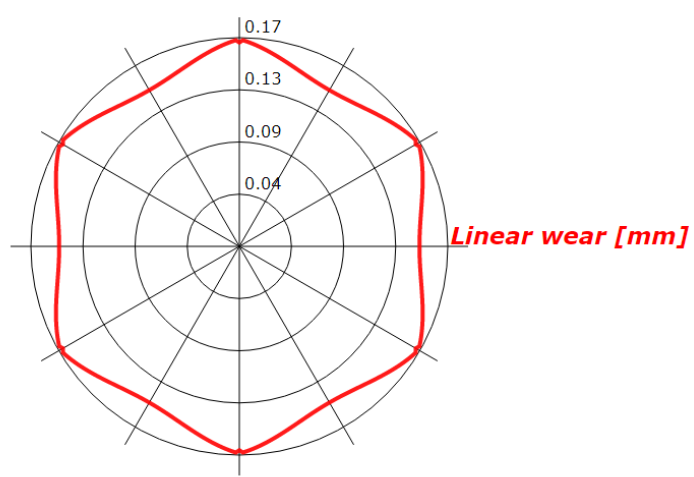

Fig. 9 Polar graph of the linear wear function $U(\omega, 1.2 \mathrm{e} 8)$ with pipe rotation $\left(60^{\circ}\right.$ every $0.2 \mathrm{e} 8$ $[\mathrm{kg}])$.

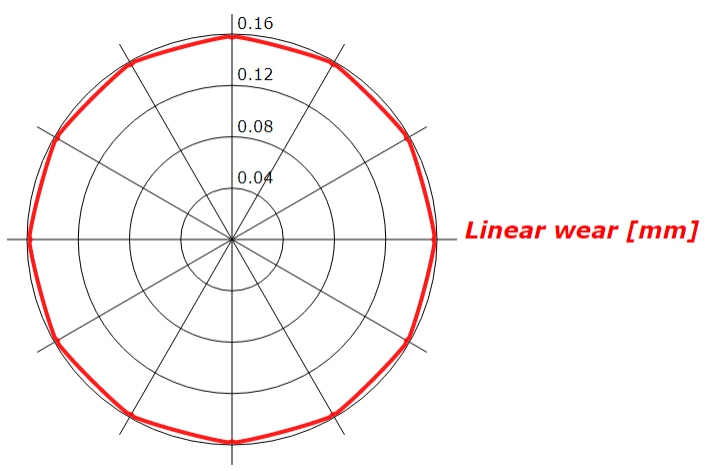

Fig. 10 Polar graph of the linear wear function $U(\omega, 1.2 \mathrm{e} 8)$ with pipe rotation $\left(30^{\circ}\right.$ every $0.1 \mathrm{e} 8$ $[\mathrm{kg}])$.

\section{MODELLING SOFTWARE}

To simulate the linear wear of a transport pipe we developed a Web browser application, which can be downloaded using the following link:

https://achmie.v.prz.edu.pl/materialy-dopobrania/materialy-ogolnodostepne

The software is free of charge and consists of four files: pipe.html (main application), plot.js (JavaScript code to generate Cartesian plots), polarPlot.js (JavaScript code to generate polar plots) and uFunction.js (JavaScript code that implements the $U$ linear wear function based on the model presented in this article). To run the software, simply open pipe.html in your browser, insert numeric data and click Refresh button to start the numerical analysis.

Before starting the simulation, it is necessary to set up the following data (like in Figure 11):

1. $\Delta m[\mathrm{~kg}]$ - mass of the material transported through the pipe during a single cycle (without pipe rotation).

2. $M[\mathrm{~kg}]$ - total mass of transported material.

3. $R[\mathrm{~mm}]$ - radius of the transport pipe.

4. $\delta\left[^{\circ}\right]$ - rotation angle of the transport pipe after a single cycle ( $\Delta m$ kilograms of material).

Then Refresh button can be used to simulate the linear wear process in the transport pipe.
Figure 12 shows the Cartesian plot of the linear wear. The $\omega$ angle in degrees goes on the $x$-axis and the $y$-axis represents linear wear in millimetres.

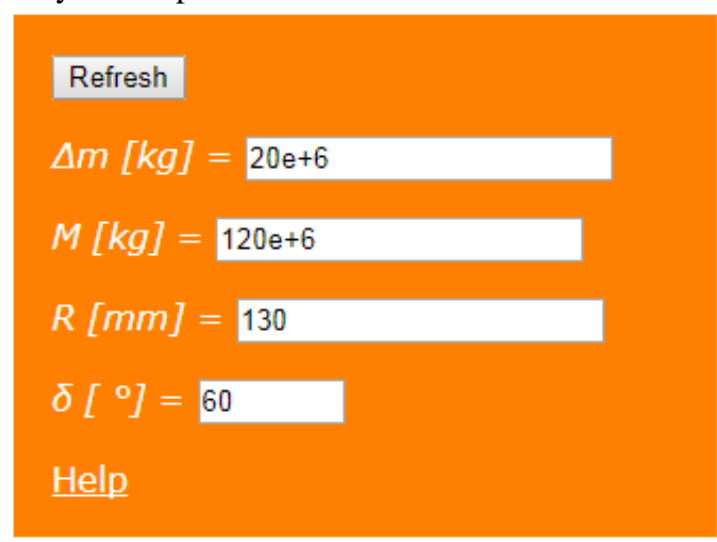

Fig. 11 Application menu with fields for numeric data.

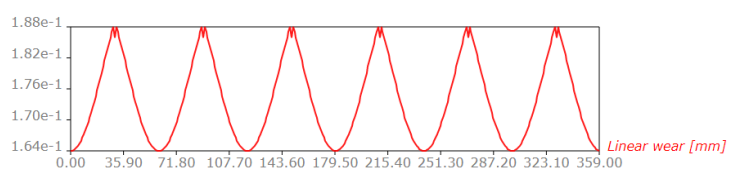

Fig. 12 Linear wear plot in Cartesian coordinate system.

Figures 13 and 14 illustrate how Next and Back buttons can be used to produce polar plots of linear wear after each cycle of pipe rotation (the transport pipe is rotated after every $\Delta \mathrm{m}$ kilograms of material).

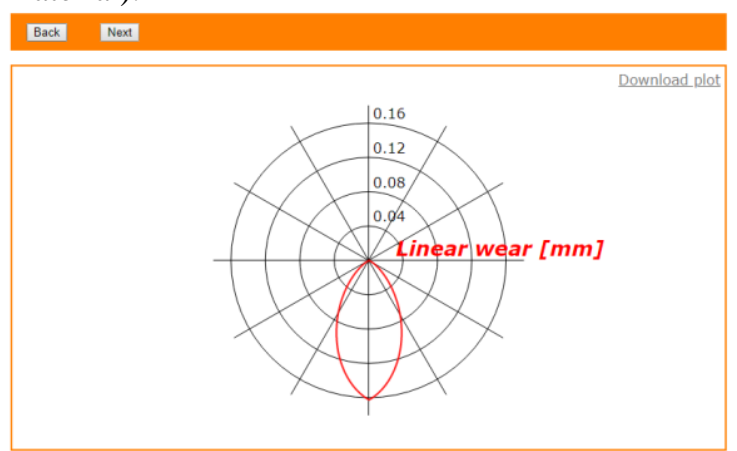

Fig. 13 Linear wear polar plot after transporting the first part of material $(\Delta \mathrm{m})$.

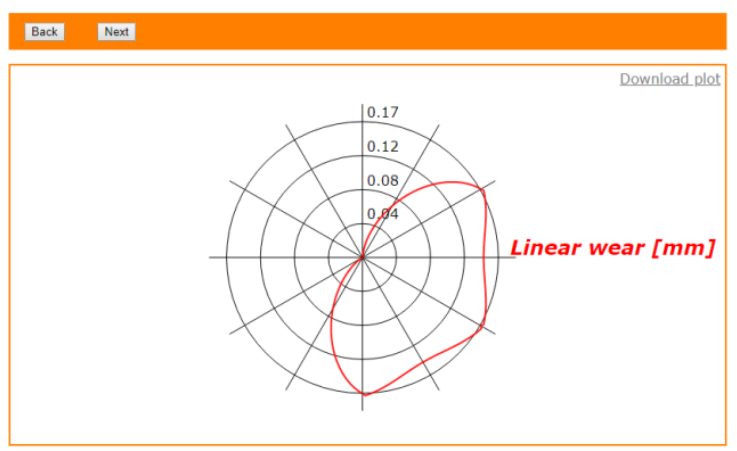

Fig. 14 Linear wear polar plot after transporting the first three parts of material $(3 \cdot \Delta m)$ and a $60^{\circ}$ cyclic pipe rotation. 


\section{CONCLUSIONS}

Both the measurements of the elements used and the theoretical model confirmed that the transport pipe wears out very unevenly. However, if we equip the pipe with a mechanism allowing it to rotate at a specific angle after transporting a given volume of loose material, its lifespan can be prolonged considerably. Although in this paper the loose material was assumed to be corn or rape, it is also possible to perform analogical calculations for other materials. However, at this point it must be stressed that various materials may require rotating the transport pipe at a different angle. The same applies to the value $h$, which depends strongly on the speed at which the material is fed into the transport pipe. In other words, the type of transported material and the fill rate of the pipe are the key factors determining the angle for which the linear wear of the pipe is relatively homogenous.

\section{REFERENCES}

1. Anand A, Curtis JS, Wassgren CR, Hancock BC, Ketterhagen WR, Predicting discharge dynamics from a rectangular hopper using the discrete element method (DEM). Chem. Eng. Sci. 2008; 63: 58215830.

2. Anshu A, et al. Predicting discharge dynamics of wet cohesive particles from a rectangular hopper using the discrete element method (DEM). Chemical Engineering Science 2009; 64(24): 5268-5275.

3. Beverloo WA, Leniger HA, Van de Velde J. The flow of granular solids through orifices. Chemical Engineering Science. 1961; 15: 260-269.

4. Brown RL, Richards JC. Profile of flow of granules through apertures. Trans. Inst. Chem. Eng. 1960; 38: 243-256.

5. Calderon $\mathrm{C}$, Olivares $\mathrm{M}$, Unac $\mathrm{R}$, Vidales $\mathrm{A}$. Correlations between flow rate parameters and the shape of the grains in a silo discharge. Powder Technology. 2017; 320: 43-50.

https://doi.org/10.1016/j.powtec.2017.07.004

6. Colonnello C, Reyes LI, Clement E, Gutierrez G. Behavior of grains in contact with the wall of a silo during the initial instants of a discharge-driven collapse. Physica A. 2014; 398: 35-42.

https://doi.org/10.1016/j.physa.2013.12.010

7. Chang CS, Converse HH, Lai FS. Flow rate of corn through orifices as affected by moisture content. Trans. of ASAE. 1984; 27(5): 1586-1589.

8. Chang SC, Converse HH, Flow rates of wheat and sorghum through horizontal orifices. Trans. of ASAE. 1988; 31(1): 300-304.

9. Glasser BJ, Goldhirsch I. Scale dependence, correlations, and fluctuations of stresses in rapid granular flows. Phys. Fluids. 2001; 13: 407-420.

10. Huang Z, Shuiqing L. DEM simulation of wet granular-fluid flows in spouted beds: Numerical studies and experimental verifications. Powder Technology 2017; 318: 337-349.

https://doi.org/10.1016/j.powtec.2017.05.009

11. Kozicki J, Donze FV. Yade-open DEM: an opensource software using a discrete element method to simulate granular material. Eng. Comp. 2009; 26 (78): 786-805.
12. Kruggel-Emden H, Wirtz S, Scherer V. A study on tangential force laws applicable to the discrete element method (DEM) for materials with viscoelastic or plastic behavior. Chem. Eng. Sci. 2008; 63:1523-1541.

13. Landolt D, Mischler S, Stemp M. Electrochemical methods in tribocorrosion: a critical appraisal, Electrochimica Acta 2001; 46(24-25): 3913-3929.

14. Lawrence J, Maier DE, Hardin J, Jones CL. Development and validation of a headspace model for a stored grain silo filled to its eave. Journal of Stored Products Research 2012; 49: 176-183. https://doi.org/10.1016/j.jspr.2012.02.002

15. Mankoc $\mathrm{C}$, et al, The flow rate of granular materials through an orifice, Granul. Matter 2007; 9: 407-414.

16. Markauskas D, Ramirez-Gomez A, Kacianauskas R, Zdancevicius E. Maize grain shape approaches for DEM modelling. Computers and Electronics in Agriculture. 2015; 118: 247-258. https://doi.org/10.1016/j.compag.2015.09.004

17. Mischler S, Debaud S, Landolt D, Wear-accelerated corrosion of passive metals in tribocorrosion systems, Journal of the Electrochemical Society. 1998; 145(3): 750-758.

18. Mort P. et al. Dense granular flow - A collaborative study. Powder Technology. 2015; 284: 571-584.

19. Neto L, Nascimento J, Marques J, Costa C, Mechanical properties of grain in silos for simulation designs. Engenharia Agricola. 2016; 36(4): 573-580.

20. Oldal I, Keppler I, Csizmadia B, Fenyvesi L. Outflow properties of silos: the effect of arching. Adv. Powder Technol. 2012; 23: 290-297. https://doi.org/10.1016/j.apt.2011.03.013

21. Remy B, Khinast JG, Glasser BJ. Discrete element simulation of free flowing grains in a four-bladed mixer. American Institute of Chemical Engineers Journal. 2009; 55(8): 2035-2048.

22. Schwedes J. Influence of wall friction on silo design in process and structural engineering. German Chem. Eng. 1985; 3: 132-138.

23. Stachowiak A, Zwierzyniecki W. Corrosive and mechanical wear calculation the integrated conception. Problems of Corrosion and Corrosion Protection of Materials. Special Issue of Journal Physicochemical Mechanics of Materials. 2004; 4(1): 98-101.

24. Stachowiak A. New means for calculating sliding pairs corrosive and mechanical wear. Zagadnienia Eksploatacji Maszyn. 2007; 42: 44-51.

25. Tardos GI, McNamara S, Talu I. Slow and intermediate flow of a frictional bulk powder in the Couette geometry. Powder Technol. 2003; 131:2339.

26. Tianqi T, Yurong H., Tong T., Dongsheng W. DEM numerical investigation of wet particle flow behaviors in multiple-spout fluidized beds. Chemical Engineering Science. 2017; 172: 79-99. https://doi.org/10.1016/j.ces.2017.06.025

27. Trinh T, Boltenhagen P, Delannay R, Valance A. Erosion and deposition processes in surface granular flows. Phys. Rev. E. 2017; 96(4): 042904. https://doi.org/10.1103/PhysRevE.96.042904

28. Widulinski L, Kozicki J, Tejchman J. Numerical Simulations of Triaxial Test with Sand Using DEM. Archives of Hydro-Engineering and Environmental Mechanics. 2009; 56(3-4): 149-171. 
29. Zhu HP, Zhou ZY, Yang RY, Yu AB. Discrete particle simulation of particulate systems: Theoretical developments, Chemical Engineering Science. 2007; 62: 3378-3396.

30. Zhu HP, Zhou ZY, Yang RY, Yu AB. Discrete particle simulation of particulate systems: A review of major applications and findings, Chemical Engineering Science. 2008; 63: 5728-5770.

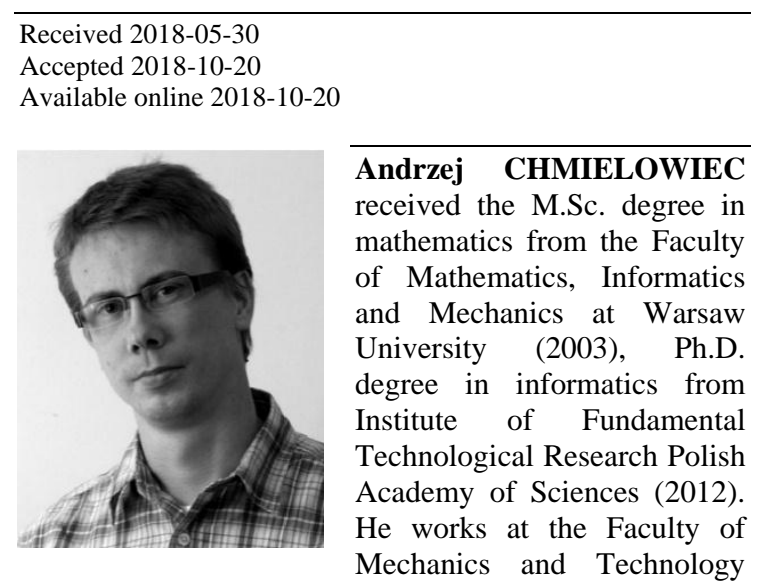

Rzeszow University of Technology.

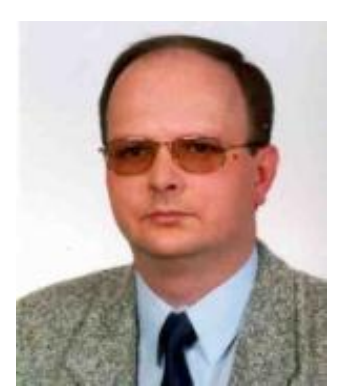

Wojciech HOMIK, DSc, Associate Professor graduate of Rzeszow University of Technology. Since 1989 employee of the Faculty of Mechanical Engineering and Aeronautics. He is engaged in problems of torsional vibration damping of crankshafts in multi-cylindrical engines. $\mathrm{He}$ is active also in designing and selection of these dampers and in problems of diagnostics, service and regeneration of them with cooperation with industry. Recently he was a member or manager of research groups and realized several projects, e.g.: start-up of the production of torsional vibration dampers of new generation with optimization algorithm, simulation and research of dampers in power transmission systems with piston combustion engines and other. He is author of app. 50 and coauthor of app. 20 scientific publications. 